\title{
Rancang Bangun Alat Monitoring Switch pada PDG ( Pressure Different Gauge ) Berbasis SMS dengan Microcontroller Arduino
}

\author{
Kadek Bintang Anjasmara ${ }^{1}$, Yoga Divayana ${ }^{2}$, Pratolo Rahardjo ${ }^{3}$ \\ Submission: 13-12-2019, Accepted: 22-03-2020
}

\begin{abstract}
In maintaining the quality of aviation fuel, before being marketed, the aviation fuel must pass through the filtering stage using a filter. The use of filters must be monitored for efficiency by using a PDG (pressure different gauge) instrument. PDG is a measuring device that is equipped with a switch and will be a disconnect when the PDG needle shows a number above 15 psi. However, filter monitoring is only done by looking at the PDG installed on each filter and the switches on the PDG have not been used at all. From this problem, the author conducted research out by designing and building a tool that can monitor switches on the PDG and provide SMS notifications. In its design, the device uses Arduino Uno as a microcontroller with a 12VDC power supply. This device is equipped with GSM SIM900A which functions to send SMS. Based on research, the highest current consumption is $0.18 \mathrm{~A}$ and the smallest is $0.11 \mathrm{~A}$. The average time for sending an SMS is 7 seconds. Based on testing the tool can work as expected. With the design and construction of this device, it is expected to help PT. Pertamina DPPU Ngurah Rai to monitoring the performance of filters in realtime so that the replacement of filter elements can be done in a timely manner and maintain the marketed aviation has good quality.
\end{abstract}

Intisari- Dalam menjaga kualitas avtur, sebelum dipasarkan avtur harus melewati tahap penyaringan menggunakan filter. Penggunaan filter harus dipantau keefektifannya dengan menggunakan instrumen PDG (pressure different gauge). PDG adalah alat ukur yang dilengkapi dengan switch dan akan terputus ketika jarum PDG menunjukkan angka diatas 15 psi. Namun saat ini pemantauan filter hanya dilakukan dengan melihat PDG yang terpasang pada setiap filter dan switch pada PDG belum dimanfaatkan sama sekali. Dari permasalahan tersebut dilakukanlah penelitian dengan merancang dan membangun sebuah alat yang dapat melakukan monitoring switch pada PDG dan memberi notifikasi SMS. Dalam perancangannya alat menggunakan Arduino Uno sebagai mikrokontroler dengan catu daya sebesar 12VDC. Alat ini dilengkapi GSM SIM900A yang berfungsi untuk mengirimkan SMS. Berdasarkan penelitian, konsumsi arus tertinggi sebesar 0,18 A dan terkecil 0,11 A. Waktu rata - rata alat dalam mengirimkan SMS sebesar 7 detik. Berdasarkan pengujian yang dilakukan alat dapat berkerja sesuai yang diharapkan. Dengan dirancang dan dibangunnya alat ini diharapkan dapat membantu teknisi PT. Pertamina DPPU Ngurah Rai dalam

${ }^{1}$ Mahasiswa, Jurusan Teknik Elektro dan Komputer Fakultas Teknik Universitas Udayana, Jln. Diponegoro Gg.8, Kav.7, no.2, Denpasar , 80222 INDONESIA (telp:082145185854; e-mail: kadekbintanga@gamil.com)

2, 3 Dosen,Jurusan Teknik Elektro dan Komputer Fakultas Teknik Universitas Udayana, Jln. Jalan Kampus Bukit Jimbaran 80361 INDONESIA (e-mail: 2yoga@unud.ac.id, pratolo@unud.ac.id ) memantau kinerja filter secara realtime sehingga penggantian element filter dapat dilakukan secara tepat waktu untuk menjaga kualitas avtur yang akan dipasarkan.

Kata Kunci-Arduino Uno, Switch, PDG, SMS

\section{PENDAHULUAN}

PT. Pertamina (Persero) selaku Badan Usaha Milik Negara Indonesia adalah perusahaan yang melakukan usaha pada sektor migas, sektor hulu hingga sektor hilir. PT. Pertamina memiliki jaringan layanan bisnis bahan bakar penerbangan atau lini bisnis aviasi. Kegiatan usaha aviasi adalah memasarkan avtur untuk perusahaan penerbangan di bandar udara (bandara) dalam negeri dan luar negeri [1]. Dalam memasarkan avtur PT. Pertamina harus menjamin kualitas avtur yang dipasarkan. Dalam menjaga kualitas avtur, sebelum dipasarkan avtur harus melalui tahap penyaringan dengan menggunakan filter. Filter ini harus dipantau efisiensinya menggunakan PDG (pressure different gauge) [2]. PDG adalah alat ukur yang dilengkapi dengan switch dan akan terputus ketika jarum PDG menunjukkan angka diatas 15 psi. Namun saat ini pemantauan filter hanya dilakukan dengan melihat secara langsung pada PDG yang terpasang pada setiap filter dan switch pada PDG belum dimanfaatkan sama sekali.

Dari permasalahan tersebut dilakukanlah penelitian yang bertujuan untuk merancang dan membangun suatu alat yang dapat melakukan monitoring proximity switch pada PDG dan memberikan notifikasi SMS ke smartphone teknisi. Sehingga teknisi dapat mengetahui kondisi filter secara realtime dan penanganan filter dilakukan dengan tepat waktu untuk menjaga kualitas avtur yang akan dipasarkan.

\section{KAJIAN PUSTAKA}

\section{A. PDG (Pressure Different Gauge)}

PDG ( Pressure Different Gauge ) adalah suatu instrumen yang digunakan untuk mengukur keefektifan filter dalam menyaring kotoran, bakteri dan surfakat lainnya yang terkadung pada avtur. Nilai PDG dapat menentukan apakah filter tersebut masih layak digunakan atau harus dilakukan penggantian element. Nilai maksimum PDG untuk filter monitor sebesar 22 psi (15 psi berdasarkan ATA 103) sedangkan untuk filter FWS sebesar 15 psi. PDG yang banyak dipakai di Indonesia khususnya Pertamina Aviasi adalah PDG dengan merek Gammon Gauge[2]. 


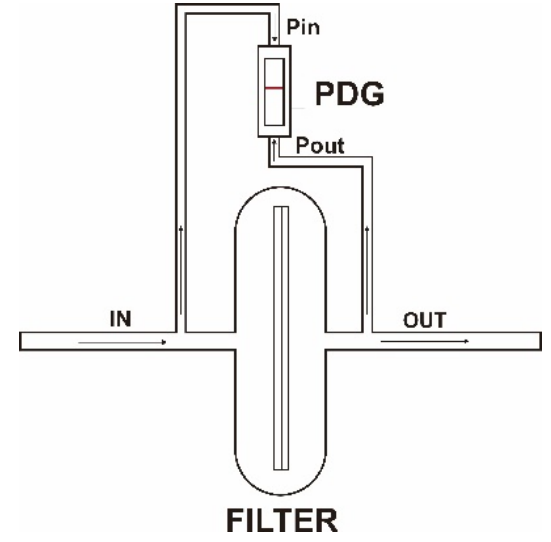

Gambar 1: Gambaran cara kerja PDG

PDG dengan merek Gammon Gauge melakukan pengukuran dengan membandingkan tekanan pada bagian atas piston yang merupakan tekanan avtur sebelum filter, akan mendorong piston ke bawah dan tekanan pada bagian bawah piston yang merupakan tekanan avtur setelah melewati filter, akan mendorong piston keatas. Saat tekanan pada bagian bawah piston lebih besar dibandingkan dengan tekanan pada bagian atas maka piston akan bergerak naik. Namun ketika tekanan di bagian bawah piston lebih kecil dari pada tekanan pada bagian atas maka piston akan bergerak turun. Semakin tinggi perbedaan tekanan mengindikasikan bahwa kotoran yang tersaring oleh filter semakin banyak sehingga menghambat aliran bahan bakar[3]. PDG memiliki suatu switch yang mana ketika piston turun hingga mencapai batas yang ditentukan maka switch yang awalnya dalam keadaan tersambung (on) akan terputus (off). Gambar 2 merupakan bentuk fisik dari PDG dengan merek Gammon.
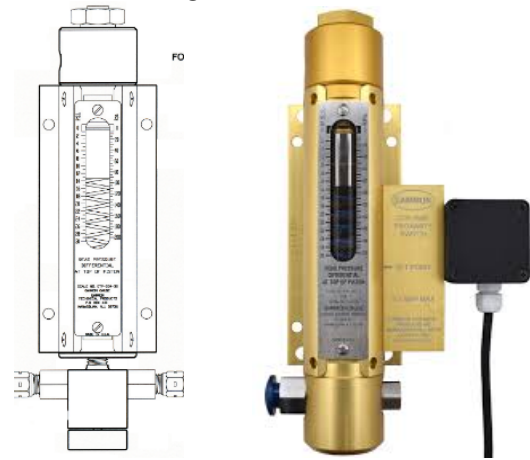

Gambar 2: Bentuk fisik PDG dengan merek Gammon

Namun adanya switch pada PDG ini belum dapat digunakan secara maksimal oleh teknisi PT.Pertamina DPPU Ngurah Rai. Teknisi harus melihat secara langsung kondisi PDG yang terpasang pada setiap filter, tentunya cara ini tidak efisien karena terdapat banyak filter yang harus dipantau dan memakan waktu yang sangat lama. Maka dari itu dirancanglah sebuah alat yang dapat melakukan monitoring kondisi switch pada PDG dan dapat memberi notifikasi berupa SMS ke smartphone teknisi ketika filter memiliki tingkat keefektifan yang rendah (PDG sudah mencapai 15 psi). Dengan adanya alat ini diharapkan teknisi dapat mengetahui kondisi PDG melalui SMS secara realtime dan dapat melakukan penggantian element secara tepat waktu.

\section{B. Arduino Uno}

Arduino Uno adalah development board mikrokontroler berbasis ATmega328. Penggunaanya yang lebih mudah dan dapat dipelajari oleh semua orang karena sifatnya yang open source adalah salah satu keunggulan dari Arduino. Untuk memprogram Arduino Uno menggunakan software Arduino IDE dengan bahasa yang digunakan ialah bahasa $\mathrm{C}$ yang telah dipermudah menggunakan fungsi - fungsi yang lebih sederhana[4]. Arduino Uno memiliki 14 pin digital yang berfungsi sebagai output maupun input dan 6 pin analog. Gambar 3 merupakan bentuk fisik dari Arduino Uno.

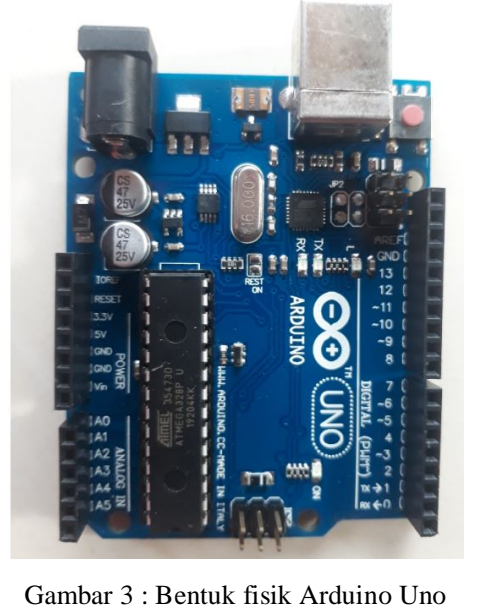

\section{Module GSM SIM900A}

Module GSM SIM900A adalah module yang berfungsi untuk mengirim dan menerima SMS, tidak hanya itu module ini juga dapat melakukan panggilan suara dan transfer data melalui GPRS dan DTMF. Untuk melakukan setiap fungsinya modul ini diperintah menggunakan AT Command dimana setiap perintah memiliki AT Command yang telah ditentukan. Module ini juga dapat bekerja pada komunikasi dual band yaitu pada frekuensi 900/1800 MHz sehingga dapat digunakan bersama dengan kartu SIM berbagai operator di Indonesia. Module SIM 900A berkeja pada tegangan 3,4 V sampai 5 V[5]. Gambar 4 merupakan bentuk fisik dari module GSM SIM900A.

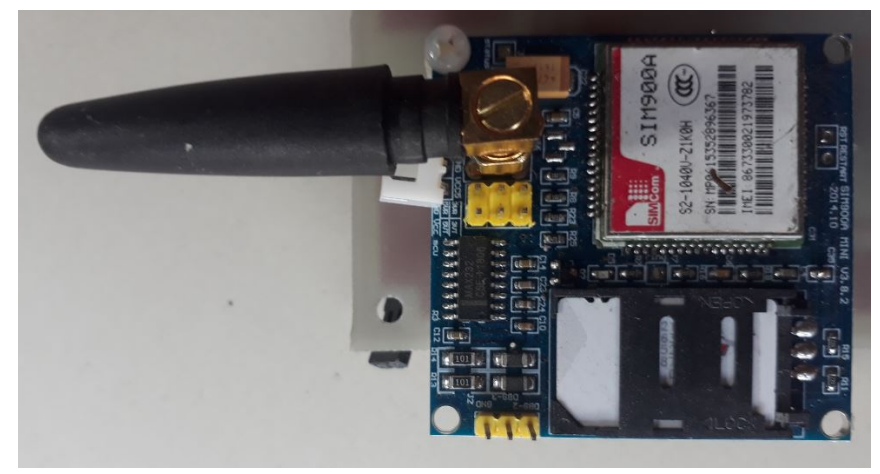

Gambar 4 : Bentuk fisik Module GSM SIM900A 


\section{SMS (Short Messasing Service)}

SMS (Short Messaging Service) adalah layanan pada sistem komunikasi nirkabel (wireless) yang menggunakan pesan singkat dalam komunikasinya. SMS pertama kali digunakan pada bulan Desember 1992, yang dikirim melalui Personal Computer (PC) ke sebuah mobilephone yang menggunakan jaringan GSM milik Vodafone Inggris. Karena perkembangan teknologi yang sangat pesat membuat perkembangan SMS ini merambah sampai ke benua Amerika dan melahirkan operator - operator yang bergerak di bidang telekomunikasi serta Teknologi yang digunakan juga berkembang seperti Time Division Multiple Access (TDMA), hingga Code Division Mutiple Access (CDMA)[6].

\section{E. DC Converter LM2596}

Module LM2596 adalah sebuah module yang berfungsi sebagai step down direct current $(D C)$ converter dengan arus output mencapai 3A dan tegangan output mencapai 25VDC. Module ini bersifat adjustable dimana output tegangannya dapat diubah - ubah dengan memutar potensio yang terdapat pada module ini. Module LM2596 ini memliki 4 pin yang terdiri dari 2 pin vec (+) dan gnd (-) sebagai input dan 2 pin output sebagai vcc (+) dan gnd (-)[7]. Gambar 5 merupakan bentuk fisik dari module LM2596

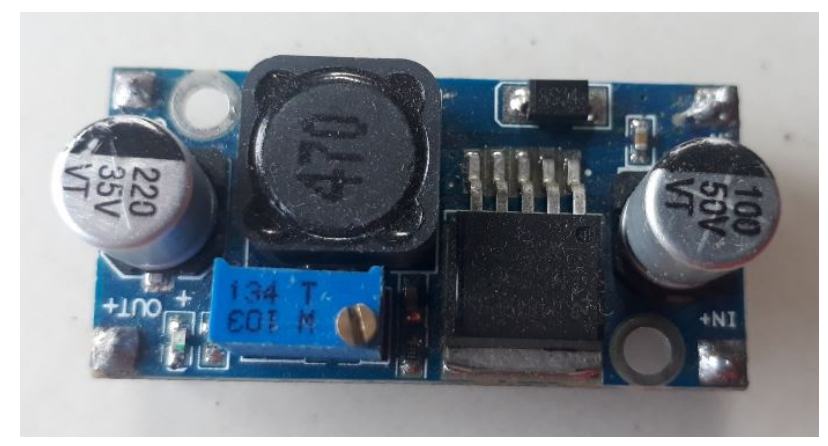

Gambar 5 : Bentuk fisik module LM2596

\section{Metode Perancangan Sistem}

\section{A. Diagram Blok Hardware}

Diagram blok hardware terdiri dari 3 bagian yaitu input, process, dan output serta terdapat juga power suplay sebagai catu daya. Gambar 6 merupakan perancangan diagram blok Hardware alat.

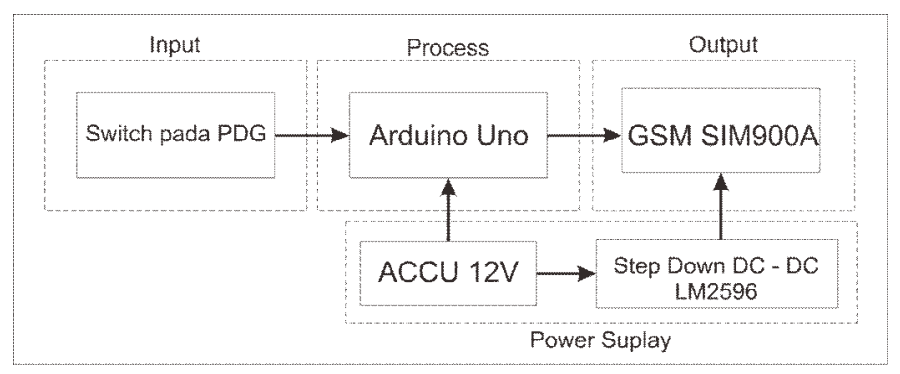

Gambar 6 : Diagram blok hardware

Kadek Bintang Anjasmara : Bangun Alat Monitoring...
Diagram blok hardware menunjukan bagaimana perancangan setiap hardware yang digunakan saling terhubung sehingga membentuk suatu sistem yang diinginkan. Accu yang digunakan untuk menyuplai alat, memiliki tegangan sebesar 12 VDC. Tegangan sebesar 12VDC akan menyuplai Arduino Uno dan secara paralel tegangan 12 VDC akan diturunkan menjadi 5VDC agar dapat menyuplai module GSM SIM900A. Switch pada PDG yang sebagai input akan dipantau oleh Arduino Uno dan module GSM SIM900A akan mengirimkan pesan sesuai perintah yang diberikan oleh Arduino Uno.

\section{B. Flowchart Keseluruhan Sistem}

Penggambaran flowchart (diagram alir) sangat penting untuk mengetahui cara kerja dari sistem yang akan dirancang. Gambar 7 merupakan penggambaran flowchart keseluruhan sistem pada alat yang akan dirancang.

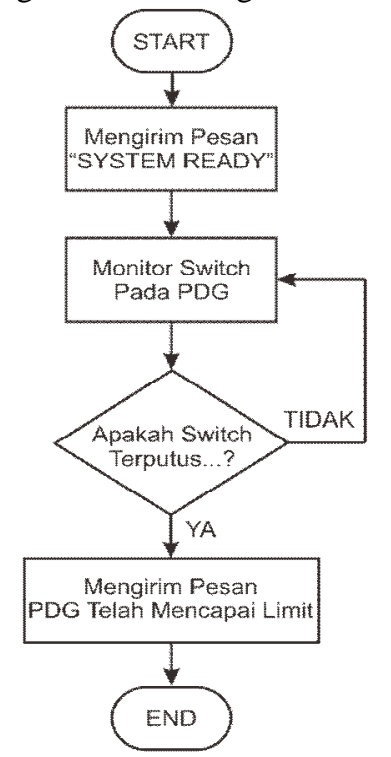

Gambar 7 : Flowchart keseluruhan sistem

Saat alat diaktifkan, maka alat akan mengirim pesan "SYSTEM READY" ke smartphone user dan setelah itu alat akan melakukan monitoring switch yang terdapat pada PDG. Apabila keadaan switch terputus maka alat akan mengirimkan SMS dengan pesan peringatan ke smartphone user.

\section{Perancangan Rangkaian Pull Up untuk Mendeteksi Kondisi Switch}

Rangkaian Pull Up adalah rangkaian yang berfungsi untuk mencegah terjadinya floating data ketika mikrokontroler membaca keadaan switch. Gambar 8 merupakan gambaran rangkaian pull up. 


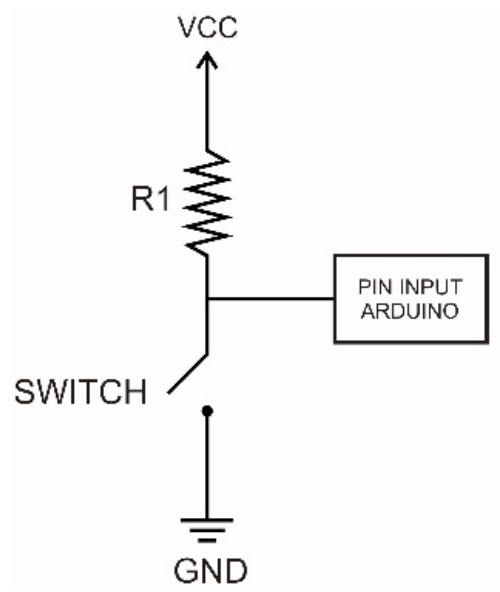

Gambar 8 : Rangkaian pull up

Ketika keadaan switch terbuka (off) maka tegangan yang dibaca oleh Arduino Uno adalah tegangan yang berasal dari VCC sehingga Arduino Uno akan membaca kondisi HIGH (1). Namun ketika keadaan switch tertutup (on) maka dari VCC akan terhubung dengan GND secara langsung. Sehingga pada Arduino Uno akan membaca kondisi sebagai $L O W(0)$ [8].

\section{Perancangan Rangkaian Alat}

Perancangan rangkain menggunakan software EAGLE. Perancangan rangkaian terbagi atas dua tahap yaitu perancangan Schematic dan perancangan Board. Hasil dari perancangan ini akan dibuat dalam bentuk rangkaian pada PCB.

1) Perancangan Schematic: Perancangan Schematic adalah perancangan rangkaian dengan menghubungkan setiap komponen yang digunakan. Gambar 9 merupakan perancangan rangkaian schematic alat.

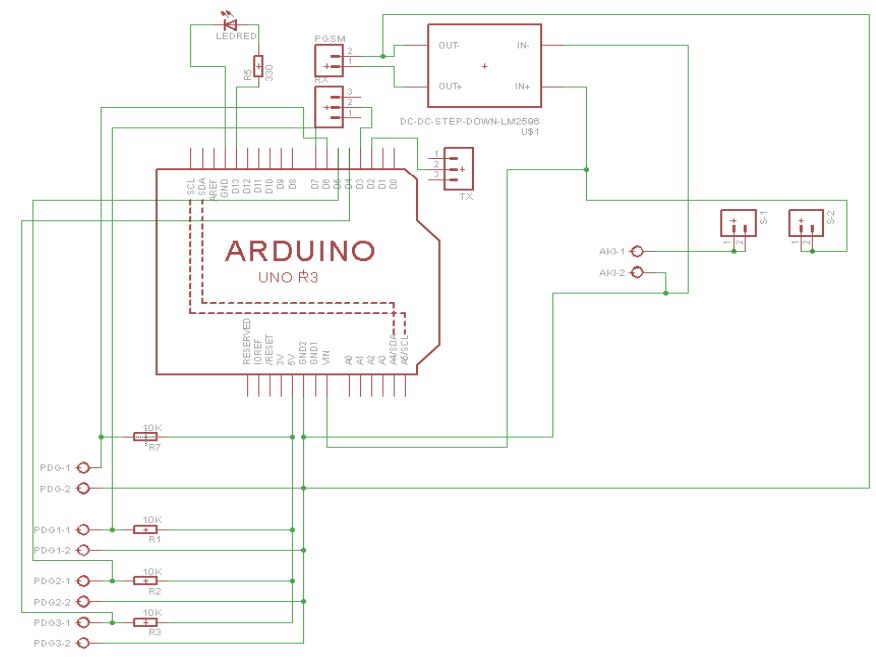

Gambar 9 : Perancangan schematic rangkaian alat

2) Perancangan Board: Perancangan Board adalah perancangan yang berupa desain dari jalur - jalur rangkaian yang sebelumnya dibuat pada perancangan Schematic. Desain dari perancangan Board akan dibuat dalam bentuk PCB.
Gambar 10 merupakan desain dari perancangan board rangkaian alat.

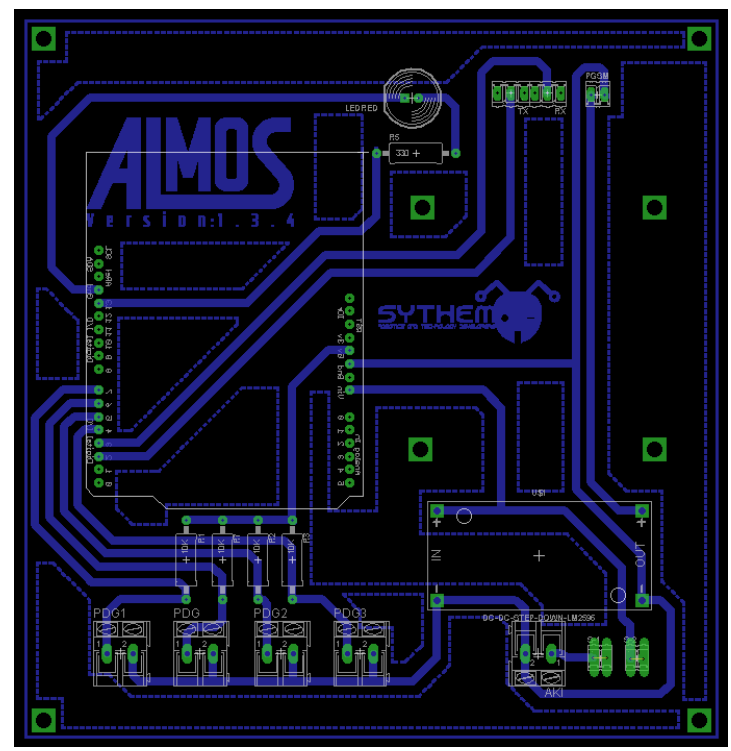

Gambar 10 : Perancangan board rangkaian alat

\section{HASIL DAN PEMBAHASAN}

\section{A. Realisasi Perancangan Alat}

Alat monitoring switch pada PDG (pressure different gauge) berbasis SMS menggunakan Arduino Uno sebagai mikrokontroler dan module SIM900A sebagai sistem komunikasi antara alat dan smartphone user melalui SMS. Alat dirancang untuk melakukan monitoring keadaan switch yang terpasang pada PDG (pressure different gauge). Ketika PDG telah mencapai 15 psi maka switch akan terputus. Terputusnya switch akan dideteksi oleh alat dan alat akan mengirim SMS ke smartphone user. Gambar 11 merupakan relalisasi perancangan alat.

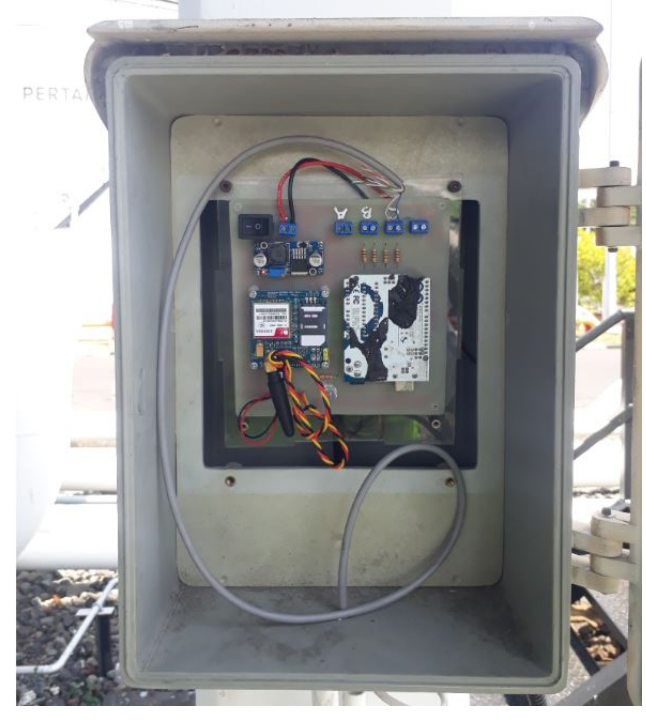

Gambar 11 : Realisasi perancangan alat

Pelindung alat terbuat dari plat besi yang telah dirancang untuk kemanan alat. Terdapat beberapa lubang untuk 
Majalah Ilmiah Teknologi Elektro, Vol. 19, No. 1, Januari - Juni 2020

DOI: https://doi.org/10.24843/MITE.2020.v19i01.P06

mengubungkan kabel catu daya dan kabel yang terhubung dengan switch PDG. Spesifikasi dari alat dapat dilihat dari table berikut.

TABEL I

SPESIFIKASI ALAT

\begin{tabular}{|c|c|c|}
\hline No & Spesifikasi & Keterangan \\
\hline 1 & Tinggi & $20 \mathrm{~cm}$ \\
\hline 2 & Panjang & $10 \mathrm{~cm}$ \\
\hline 3 & Lebar & $10 \mathrm{~cm}$ \\
\hline 4 & Berat Keseluruhan & $180 \mathrm{~g}$ \\
\hline 5 & Tegangan Input & 12 Volt \\
\hline 6 & Arus Maksimal & 3 Ampere \\
\hline 7 & Mikrokontroler & Arduino Uno \\
\hline 8 & Sistem Komunikasi & SIM900A \\
\hline 9 & Jumlah Pendeteksi Switch & 4 \\
\hline
\end{tabular}

\section{B. Pemasangan Alat Dilapangan}

Tempat pemasangan alat berlokasi di PT. Pertamina(persero) DPPU Ngurah Rai. Filter yang digunakan dalam pengujian adalah filter yang berfungsi untuk menyaring avtur dari air. Kabel penghubung antara alat dengan switch menggunakan kabel LAN. Catu daya yang digunakan adalah Accu dengan tegangan 12VDC dan dipasang terpisah dari alat.

Pemasangan alat monitoring switch pada PDG ini harus pada tempat yang aman dengan pelindungan yang harus diperhatikan karena lingkungan di sekitar alat adalah bahan bakar minyak yang mudah terbakar. Alat harus terhindar dari percikan avtur, air, dan benda - benda lainya yang mengakibatkan terjadinya kerusakan pada alat. Berikut adalah komponen yang ditambahkan dalam menjaga keamanan alat.

1) Body Pelindung Alat : Body pelindung alat merupakan sebuah box besi yang dilengkapi dengan pintu penutup. Tujuan dari penggunaan body pelindung adalah untuk melindungi alat dari percikan - percikan avtur, air, dan benda lainnya yang akan menyebakan kerusakan pada alat. Gambar 12 merupakan body pelindung yang telah terpasang pada alat.

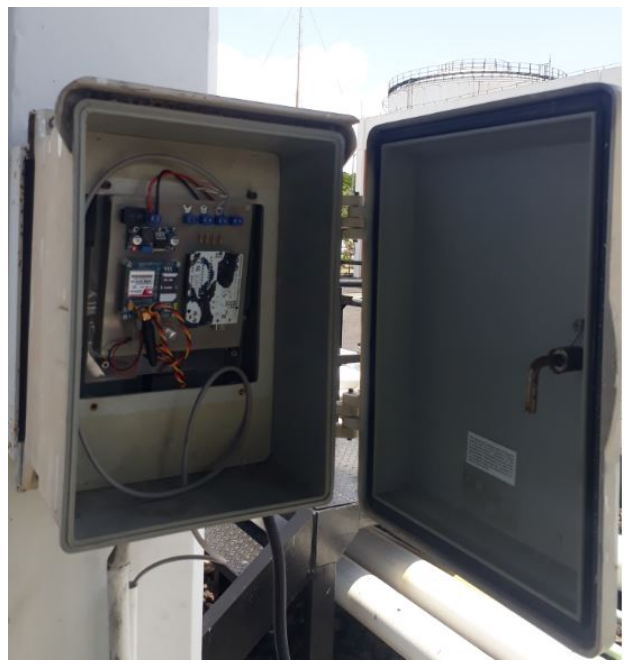

Gambar 12 : Body pelindung alat

Kadek Bintang Anjasmara : Bangun Alat Monitoring...
2) Body Pelindung Accu: Pelindung Accu juga menggunakan box yang berbahan plat besi namun lebih tebal. Асси haruslah ditempatkan di tempat yang benar - benar aman agar tidak memicu ledakan yang menyebabkan kebakaran. Gambar 13 merupakan body pelindung yang terpasang pada $A c c u$.

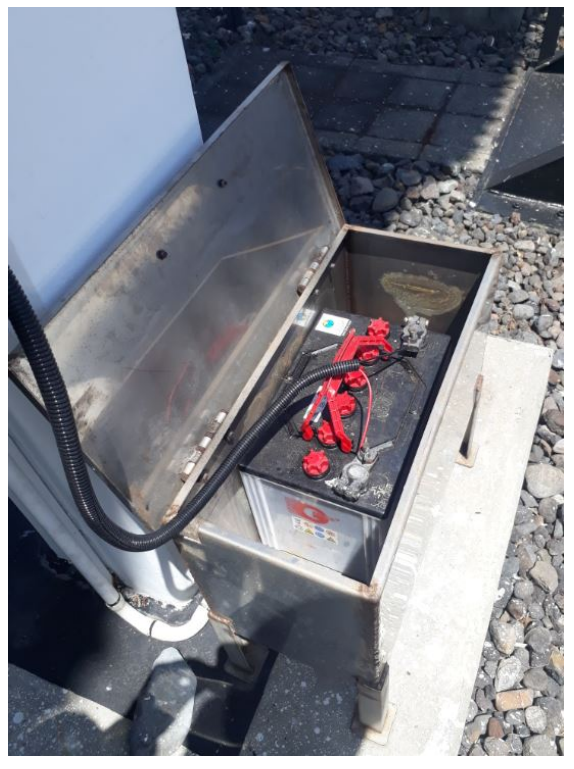

Gambar 13 : Body pelindung Accu

3) Pelindung Kabel : Kabel yang terhubung dengan Accu dan kabel terhubung dengan PDG haruslah diberi perlindungan. Kabel yang terhubung dengan Асси menggunakan selang dengan ukuran 0,5 inci dan kabel yang terhubung dengan PDG dilindungi pipa dengan ukuran 0,5 inci. Gambar 14 merupakan pelindung kabel yang telah terpasang.
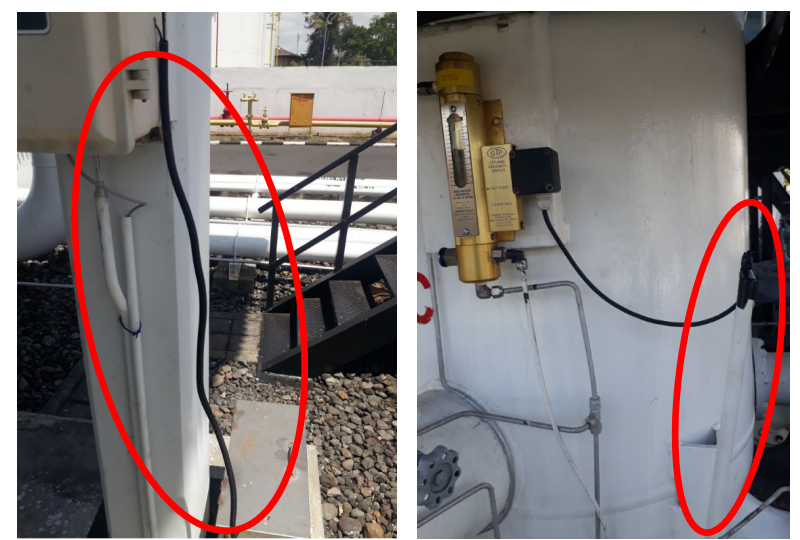

Gambar 14 : Pelindung kabel

\section{Pengujian Pembacaan Switch Menggunakan Arduino Uno.}

Pembacaan switch menggunakan Arduino Uno dilakukan dengan mengamati data dari serial monitor yang telah disediakan oleh software Arduino IDE. Switch akan diganti dengan dua buah kabel yang nantinya akan di putus dan

p-ISSN:1693 - 2951; e-ISSN: 2503-2372 
disambung untuk pembacaan data pada Arduino Uno. Ketika switch terputus Arduino Uno akan membaca data dengan logika HIGH (1). Gambar 15 merupakan pembacaan data switch yang terputus menggunakan serial monitor.

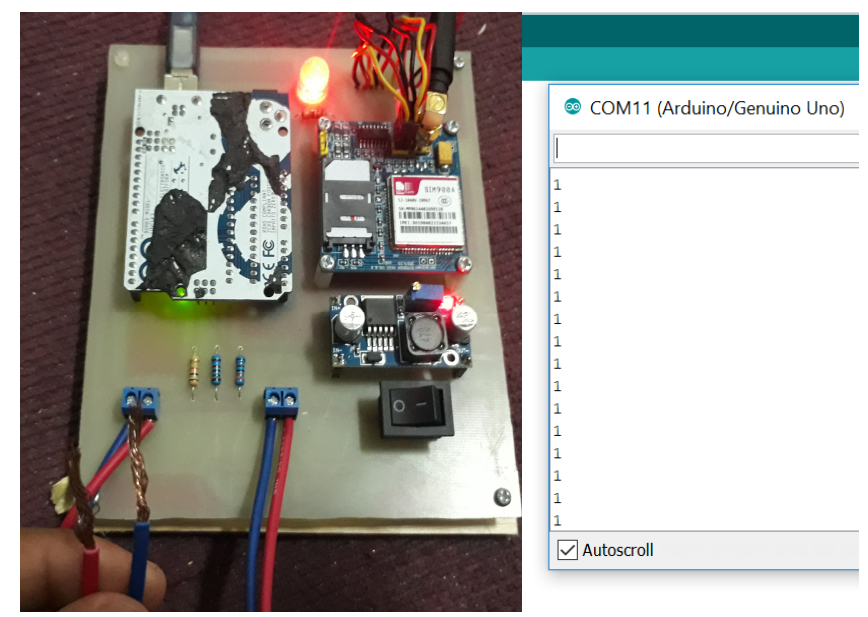

Gambar 15 : Pembacaan switch terputus yang berlogika HIGH (1)

Ketika switch tersambung maka Arduino Uno akan membaca data switch dengan logika $\operatorname{LOW}(0)$. Gambar 16 merupakan pembacaan data switch yang tersambung menggunakan serial monitor.
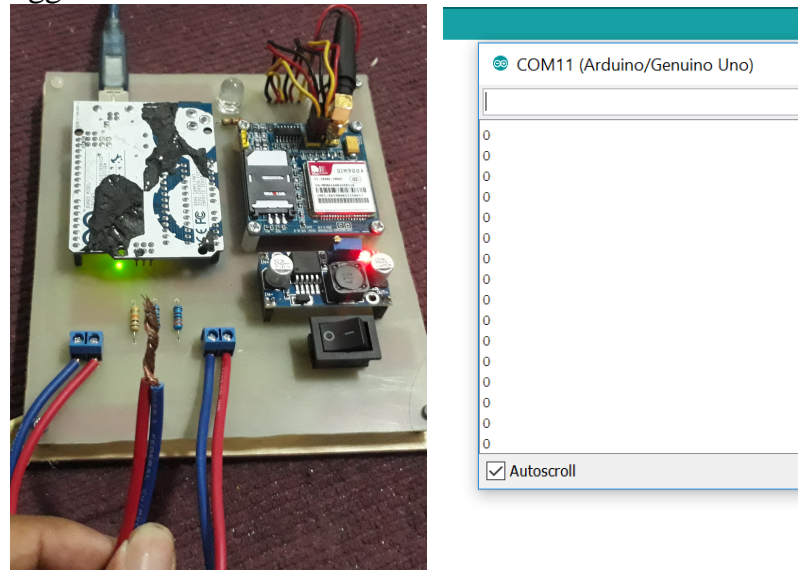

Gambar 16 : Pembacaan switch tersambung yang berlogika LOW (0)

Hasil pengujian pembacaan switch menunjukan bahwa Arduino Uno dapat membaca kondisi switch dengan benar dan sesaui dengan teorinya. Sehingga dalam pengujian ini alat telah berhasil untuk membaca kondisi switch.

\section{Pengujian Tegangan pada setiap Komponen}

Pengujian tegangan pada setiap komponen berfungsi untuk mengetahui apakah setiap komponen yang digunakan telah mendapatkan tegangan yang sesaui dengan spesifikasi setiap masing - masing komponen. Komponen yang akan diukur yaitu tegangan input pada Arduino Uno, tegangan input pada Module GSM SIM 900A, dan tegangan input serta output pada Module LM2596. Gambar 17 merupakan pengukuran pada komponen yang digunakan.
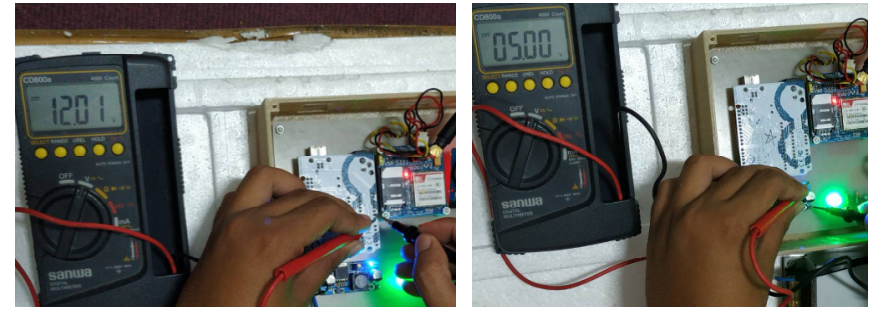

Gambar 17 : Pengukuran tegangan pada komponen

Hasil dari pengukuran yang telah dilakukan dapat dilihat pada tabel berikut.

TABEL III

HASIL PENGUKURAN TEGANGAN PADA KOMPONEN

\begin{tabular}{|c|l|c|c|c|}
\hline No & \multicolumn{1}{|c|}{ Pengukuran } & Hasil & Target & Status \\
\hline 1 & $\begin{array}{l}\text { Tegangan Input } \\
\text { Arduino }\end{array}$ & $12,01 \mathrm{~V}$ & $12 \mathrm{~V}$ & Sesuai \\
\hline 2 & $\begin{array}{l}\text { Tegangan Input } \\
\text { GSM SIM900A }\end{array}$ & $5.00 \mathrm{~V}$ & $5 \mathrm{~V}$ & Sesuai \\
\hline 3 & $\begin{array}{l}\text { Tegangan Input } \\
\text { LM2596 }\end{array}$ & $12,01 \mathrm{~V}$ & $12 \mathrm{~V}$ & Sesuai \\
\hline 4 & $\begin{array}{l}\text { Tegangan Output } \\
\text { LM2596 }\end{array}$ & $5,01 \mathrm{~V}$ & $5 \mathrm{~V}$ & Sesuai \\
\hline
\end{tabular}

Setiap komponen memiliki tegangan kerja yang berbeda beda. Menurut data sheet Arduino Uno memiliki tegangan input sebesar $12-5 \mathrm{~V}$, dari pengukuran yang telah dilakukan Arduino Uno mendapatkan tegangan input sebesar $12,01 \mathrm{~V}$, sehingga dapat dikatakan tegangan yang diterima telah sesuai dengan data sheet. Module SIM 900A memiliki tegangan input sebesar $5 \mathrm{~V}$ dan pada pengukurannya, module SIM900A mendapatkan tegangan input sebesar $5 \mathrm{~V}$, sehingga hasil pengukuran yang didapatkan telah sesuai dengan data sheet. LM2596 yang bertugas menurunkan tegangan 12V menjadi $5 \mathrm{~V}$ telah sesuai dengan hasil pengukuran yang dilakukan dimana tegangan input yang terukur sebesar $12,01 \mathrm{~V}$ dan tegangan output-nya sebesar 5,01 V.

\section{E. Pengujian Pengukuran Arus pada Alat}

Pengukuran arus yang mengalir pada alat bertujuan untuk mengetahui konsumsi arus yang dibutuhkan alat untuk beroperasi. Pengukuran arus dilakukan pada beberapa kondisi yang terjadi ketika alat sedang beroperasi, seperti pada saat pairing sinyal, saat stand by, dan saat mengirimkan pesan SMS. Gambar 18 : menunjukan grafik konsumsi arus ketika alat sedang beroperasi. 


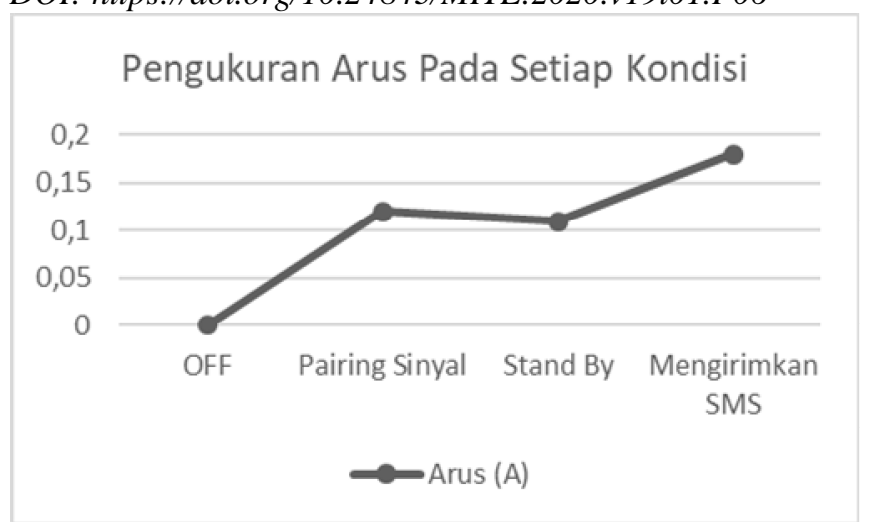

Gambar 18 : Pengukuran konsumsi arus ketika alat sedang beroprasi

Berdasarkan hasil pengujian arus yang telah dilakukan, bahwa konsumsi arus tertinggi saat alat beroperasi sebesar 0,18 A dan arus terkecil sebesar 0,11 A. Maka dari itu, untuk mengoperasika alat dibutuhkan sumber catu daya yang dapat menyuplai arus minimal sebesar 0,2 A. Nilai ini diperoleh dengan menjumlahkan $20 \%$ dari nilai arus maksimal ditambah dengan nilai arus maksimal itu sendiri.

\section{F. Pengujian Alat dalam Mengirimkan SMS}

Pengujian Alat dalam mengirimkan SMS dilakukan dengan menurunkan tekanan pada bagian bawah PDG sehingga jarum penunjuk angka pada PDG turun. Ketika jarum penunjuk turun hingga 15 psi. Maka alat akan mengirimkan SMS ke nomer smartphone user. Gambar 19 menunjukan kondisi PDG yang telah mencapai 15 psi dan notifikasi SMS yang telah diterima oleh user.
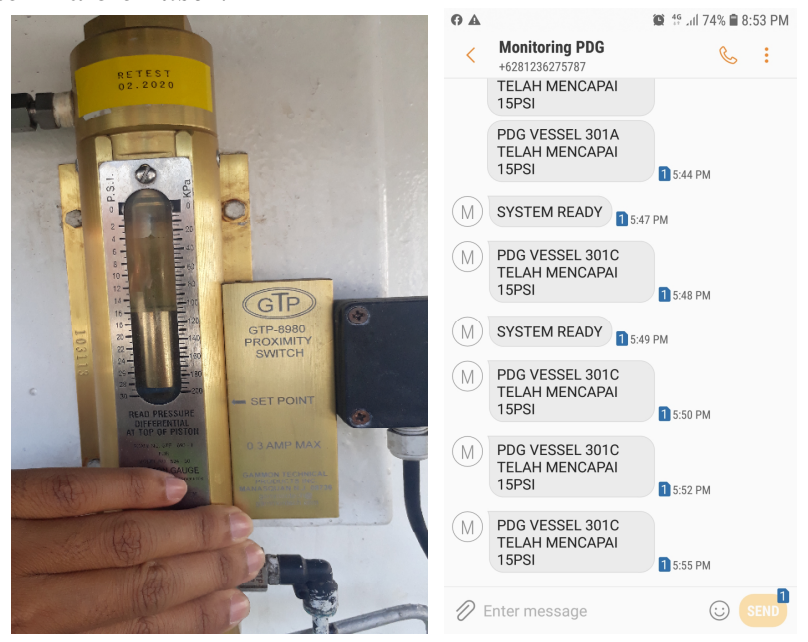

Gambar 19 : Jarum PDG menunjukan angka 15 psi dan pesan SMS yang diterima oleh user

Berdasarkan hasil pengujian diatas menujukan bahwa alat telah berhasil dalam mengirimkan notifikasi SMS ketika switch pada PDG terputus. Selanjutnya pada pengujian ini juga melakukan penghitungan waktu ketika jarum PDG mencapai 15 psi hingga SMS diterima oleh smartphone user. Pengujian bertujuan untuk mengetahui waktu rata - rata yang dibutuhkan alat dalam mengirimkan pesan SMS. Waktu rata Kadek Bintang Anjasmara : Bangun Alat Monitoring... rata diperoleh dengan melakukan percobaan sebanyak 5 kali. Berdasarkan dari hasil pengujian diatas, bahwa waktu rata rata alat dalam mengirimkan SMS sebesar 7 detik. Berikut merupakan tabel data waktu hasil pengujian alat dalam mengirimkan SMS.

TABEL IIIII

DAta WaKtu Hasil PENGUJian Alat DALAm MENGIRIMKAn SMS

\begin{tabular}{|c|c|}
\hline Percobaan ke- & Waktu (detik) \\
\hline 1 & 5 \\
\hline 2 & 9 \\
\hline 3 & 7 \\
\hline 4 & 8 \\
\hline 5 & 6 \\
\hline Rata - Rata & $\mathbf{7}$ \\
\hline
\end{tabular}

\section{G. Tata Cara Penggunaan Alat}

Adapun tata cara penggunaan alat agar dapat bekerja secara maksimal. Berikut adalah langkah - langkah tata cara penggunaan alat.

1) Sebelum menggunaakan alat pastikan terlebih dahulu hal - hal sebagai berikut.

- Pastikan sumber catu daya yang digunakan sebesar 12VDC. Jika menggunakan tegangan AC 220V (Listrik PLN) gunakanlah adapter dengan tegangan output sebesar 12V DC dengan arus minimal 5A.

- Pastikan SIM Card GSM pada alat telah terisi pulsa minimal sebesar 5.000.

- Pastikan alat telah terhubung dengan switch pada PDG.

- Pastikan nomer tujuan pengiriman SMS oleh alat sesuai dengan nomer pengguna (user)

2) Untuk mengaktifkan alat tekan switch saklar pada alat.

3) Setelah switch saklar ditekan maka alat akan menyala. Tunggu beberapa saat sampai alat mengirim SMS dengan pesan "SISTEM READY" ke nomer pengguna (user).

4) Setelah pesan "SISTEM READY" diterima maka alat sudah melakukan monitoring switch pada PDG secara terus menerus.

5) Ketika jarum penunjuk pada PDG mencapai 15 psi maka switch akan terputus. Pada saat itu juga alat akan mengirimkan SMS dengan pesan yang telah ditentukan.

6) Sebelum melakukan tindakan di lapangan, matikan terlebih dahulu alat dengan cara menekan switch saklar pada alat. Ini dilakukan agar alat tidak melakukan pengiriman SMS secara terus - menerus.

7) Setelah melakukan tindakan maka alat dapat diaktifkan kembali.

\section{KESIMPULAN}

p-ISSN:1693 - 2951; e-ISSN: 2503-2372 
Alat monitoring switch pada PDG berbasis SMS adalah sebuah sistem yang menggunakan mikrokontroler Arduino Uno yang bertujuan untuk memberikan notifikasi berupa SMS ke user ketika nilai pengukuran PDG melebihi 15 psi. Dalam pengiriman SMS, alat ini dilengkapi dengan Module SIM900A dengan tegangan kerja 5 VDC. Alat ini disuplay dengan catu daya sebesar 12 VDC dan dilengkapi penurun tegangan LM2596 dengan output 5 VDC. Berdasarkan pengujian yang telah dilakukan alat dapat mendeteksi keadaan switch yang terpasang pada PDG dan dapat mengirimkan SMS ke smartphone user. Pengiriman pesan SMS memiliki rentan waktu rata - rata sebesar 7 detik. Setiap komponen yang digunakan telah mendapatkan tegangan yang sesuai dengan data sheet dan setiap komponen mampu bekerja dengan baik. Konsumsi arus terbesar saat alat sedang beroperasi terukur sebesar 0,18 A dan yang terkecil sebesar 0,11 A. Dengan adanya alat ini diharapkan teknisi PT. Pertamina DPPU Ngurah Rai dapat mengetahui kondisi PDG ketika filter sudah tidak efektif lagi secara realtime dan penggantian element pada filter dapat dilakukan secara tepat waktu sehingga kualitas avtur yang akan dipasarkan tetap memiliki kualitas yang baik.

\section{UCAPAN TERIMA KASIH}

Ucapan terima kasih disampaikan kepada semua pihak yang berkontribusi pada penelitian ini khususnya kepada para teknisi PT. Pertamina(persero) DPPU Ngurah Rai yang membantu dalam pemasangan alat, sehingga penelitian ini dapat terlaksana dengan baik.

\section{REFERENSI}

[1] PT.Pertamina, Aviation.[Online]. Available: https://www.pertamina.com/id/aviation

[2] Lukman Saputra (2019)Bagaimana Mengoreksi Nilai PDG Pada Aktual Flowrate. [Online]. Available: https://airsideportal.wordpress.com/2019/02/04/bagaimanamengkoreksi-nilai-pdg-pada-aktual-flowrate/

[3] "Gammon Gauge data sheet" Gammon, Manasquan, USA.

[4] Pendro Paulo de Jesus Costa Henriques, I. G. A. P. Raka Agung, Lie Jasa.,2018. Rancang Bangun Sensor Jarak sebagai Alat Bantu Memarkir Mobil berbasis Mikrokontroler Arduino Uno. Universitas Udayana, 17(1), pp. 72-79

[5] I Gusti Agung Made Yoga Mahaputra, I. G. A. P. Raka Agung, Lie Jasa.,2019. Rancang Bangun Sistem Keamanan Sepeda Motor Dengan GPS Tracker Berbasis Mikrokontroler dan Aplikasi Android. Universitas Udayana.

[6] Iqbal Kamil Siregar, Faisal Taufik, ,2017.Perancangan Aplikasi SMS Alert Berbabsis Web. STMIK Royal Kisaran.

[7] Febi Amin Lutfi.,2018.Perancangan Purwarupa Sistem Peringatan Kebocoran Gas Liquefied Petroleum Gas (LPG). Universitas Teknologi Yogyakarta.

[8] J. Wundelich,Ph.D,2016.Floating Inputs and Resistor For Pull-UP, Pull-Down, and Current Limiting.

[9] "GSM SIM900 data sheet" SIMCom, Sanghai, China

[10] Arduino (2020). Arduino. [Online]. Available : https://www.arduino.cc/en/Main/Products 